\title{
Effects of Tenascin-C (TNC) Knockdown on Global Genes Expression
}

\author{
Ali S. Alharth ${ }^{1, *}$, Sherien M. El-Daly ${ }^{2}$ \\ ${ }^{1}$ Department of Public Health, Ministry of Health, Riyadh, Saudi Arabia \\ ${ }^{2}$ Department of Medical Biochemistry, National Research Center, Cairo, Egypt \\ *Corresponding author: alharth_a@yahoo.com
}

Received April 02, 2015; Revised April 12, 2015; Accepted April 22, 2015

\begin{abstract}
The extracellular matrix protein tenascin-C (TNC) is up-regulated in many cancers including breast cancer. TNC is associated with tumour progression and poor prognosis. The aim of this study was to investigate the effects of TNC knockdown on global gene expression in TNC expressing invasive breast cancer cell lines. Breast cancer cell lines (MDA-MB-231 and MDA-MB-436) were transfected with small interfering RNA (siRNAs) targeting total TNC. cDNA microarray was used to analyse the effects of TNC knockdown on global gene expression at the mRNA level. Microarray analysis following total TNC knockdown revealed significant changes in gene expression: CREBL2, YWHAE and RRAS2 showed down regulation and $Q K I$ was specifically up-regulated. In conclusion, the silencing of TNC expression caused significant alteration on global genes expression associated with tumour progression.
\end{abstract}

Keywords: Microarray, TNC Knockdown, siRNA

Cite This Article: Ali S. Alharth, and Sherien M. El-Daly, "Effects of Tenascin-C (TNC) Knockdown on Global Genes Expression.” American Journal of Medical and Biological Research, vol. 3, no. 2 (2015): 62-67. doi: 10.12691/ajmbr-3-2-3.

\section{Introduction}

The extracellular matrix (ECM) functions as a scaffold to maintain tissue and organ structure. The ECM also regulates pivotal physiological processes such as cell proliferation, migration, differentiation, growth and survival [1]. TNC is one glycoprotein, which is highly expressed in the stroma of many solid tumours and in breast cancer in particular [2]. In vitro studies have shown that TNC modulates cell signalling pathways involving Wnt, mitogen-activated protein kinase (MAPK), focal adhesion kinase (FAK) and Rho ([3,4,5]). By analysing the effects of TNC on global gene expression using cDNA microarray, Ruiz [4] found that TNC stimulates tumour cell proliferation in glioma cells by down-regulating the expression of tropomyosin-1, subsequently leading to cell spreading by destabilisation of actin stress fibres. TNC differentially regulates genes associated with several pathways, such as endothelial receptor type A (ENDRA), MAPK, and the Wnt inhibitor dickkopf-1 (DKK1) [5]. The aims of this study were to investigate the effects of TNC knockdown on global gene expression in highly invasive breast cancer cell lines, and to show the most significant up - or down-regulation genes associated with invasion, proliferation and migration. The results of the study show that TNC silencing significantly regulates genes expression associated with tumour progression.

\section{Materials and Methods}

\subsection{Cell Lines}

Breast cell lines (MDA-MB-231, MDA-MB-436) were obtained from American Type Culture Collection (Rockville, MD, USA). MDA-MB-436 cell line was grown in RPMI with 10\% FBS. MDA-MB-231 cell line was grown in DMEM containing $2 \mathrm{mM}$ L-glutamine and 10\% FBS (Invitrogen Life Science, Carlsbad, CA, USA).

\section{2. siRNA Transfection of breast carcinoma cell lines}

Breast cancer cell lines were transfected with siRNA targeting total TNC (sense and antisense siRNA targeting TNC at exon 24 are 5'CGCGAGAACUUCUACCAAAtt3' and 5'UUUGGUAGAAGUUCUCGCGtc3), and scrambled siRNA as a negative control. Lipofectamine 2000 was used as transfection reagent (Invitrogen, UK). The transfection incubation periods were two time points (24 and 48 hours).

\subsection{Reverse Transcription and Quantitative Polymerase Chain Reaction (RT-qPCR)}

RNA was extracted from breast cancer cell pellets resuspended in Tri Reagent. mRNA was isolated using

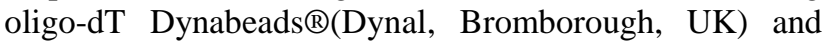
reveres transcription was performed as described previously ([6,7]). Total TNC expression was analysed using inventoried Taqman assays (Applied Biosystems Hs01115654_m1). The relative expression (RE) of TNC knockdown was calculated the formula : 


$$
R E=2-(\Delta \Delta C t)[7] .
$$

\subsection{Microarray Studies}

Microarray analysis carried out on breast cancer cell lines (MDA-MB-231, MDA-MB-436) transfected with siRNAs targeting total TNC. The isolated RNA using RNeasy Mini Kit were analysed by Almac Diagnostics, UK. The raw data (CEL files) were normalised and analysed using Partek ${ }^{\circledR}$ Genomics Suite ${ }^{\mathrm{TM}}$ 6.5, build 6.10.1129 (Partek Inc, USA, http://www.partek.com/). To identify the top lists of differentially expressed genes, the normalised and filtered data set was further analysed to deduce the most highly significant up- and downregulated genes, and also to determine sample relationships based through hierarchical cluster (HCL). Prior to background correction, raw probe signal intensity values were pre-adjusted for target GC content and probe sequence. Background correction using the robust multiarray average (RMA) method [8] including quantile normalisation and median polish probe set summarisation was then performed. The effects of normalisation were then observed through the comparison of un-normalised and normalised data using Box-Plots. Following normalisation, the filtering of array data to deduce markers of significant difference was carried out according to a significance of $\mathrm{p} \leq 0.05$ with false discovery rate (FDR) and thresholded with $\geq 2$ fold changes.

\subsection{Pathway Analysis}

A functional annotation cluster and pathway analysis was performed on 902 (642 up and 260 down) genes identified of siRNA transfection in both cell lines using the Database for Annotation, Visualization and Integrated Discovery (DAVID).

\subsection{Statistical Analysis}

Statistical analysis was performed using GraphPad Prism 5 for Windows (GraphPad Software, Inc., USA). All assays used to determine the effects of siRNA employed a Two-Way Analysis of Variance (Two-way ANOVA) and Post-hoc Tukey's test in order to test the significant variance between cells transfected with TNC siRNAs compared to cells transfected to scrambled siRNA. All tests were two-sided and $\mathrm{P}<0.05$ was considered significant.

\section{Results}

It is known that siRNAs regulate gene expression by degradation of the targeted gene and inhibiting translation [9]. The knowledge about total TNC knockdown on gene expression on breast cancer cell lines is limited. In this study, the efficiency of total TNC siRNA compared to the scrambled siRNA control, RNA collected from the transfected cell lines at two time points post transfection (24 and $48 \mathrm{hrs}$ ) was analysed using RT-qPCR. Real time qPCR analysis of assays specific to total TNC (targeting exon 17-18), showed statistically significant down regulation $(p<0.001)$ of all mRNA species at both 24 and 48 hrs (Figure 1).

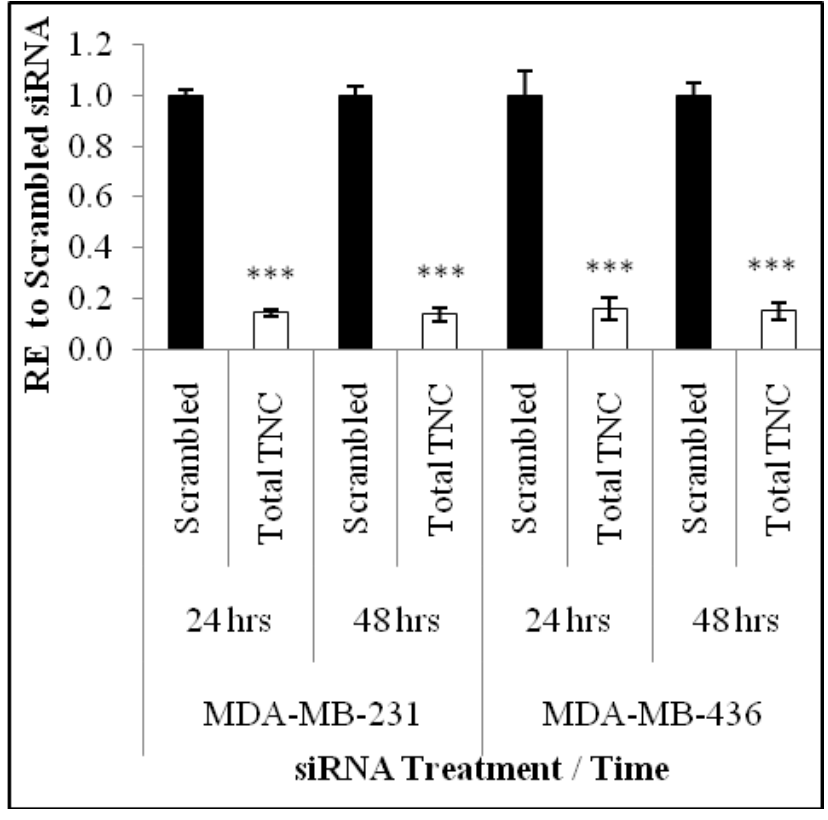

Figure 1. Relative expression (RE) means and ( \pm SEM) of TNC between samples in breast cancer cell lines transfected with total TNC siRNA at 24 and 48 hrs post transfections compared to scrambled siRNA. All results are highly significant as indicated by the stars $(* * *=\mathrm{p} \leq 0.001)$.

\subsection{Microarray Results}


\section{Cell-line}

MDA-MB-231

$\square \mathrm{MDA}-\mathrm{MB}-436$
iRNA treatment

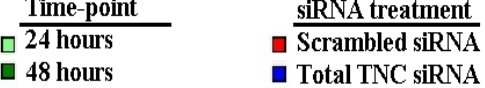

Figure 2. Hierarchical clustering of samples identifies two main clusters, representing the two different cell lines. Within each cluster, samples were again divided by siRNA treatment and time point. Red, positive $\log _{2}$ ratio; Green, negative $\log _{2}$ ratio 
Table 1. Top 20 regulated genes in breast cancer cell lines after total TNC knockdown determined by GeneChip microarray

\begin{tabular}{|c|c|c|c|c|c|}
\hline \multirow{2}{*}{ Gene Symbol } & \multirow{2}{*}{ NCBI accession number } & \multirow{2}{*}{ Description } & \multicolumn{3}{|c|}{ Fold change } \\
\hline & & & MDA-MB-231 & MDA-MB-436 & Average \\
\hline DISC1 & $\begin{array}{l}\text { NM_001012957, } \\
\text { NM_001012958, } \\
\text { NM_001012959, }\end{array}$ & Disrupted in schizophrenia 1 & 3.7 & 7.35 & 5.5 \\
\hline OLFML3 & NM_020190 & Olfactomedin-like 3 & 4 & 5.55 & 4.8 \\
\hline EMP2 & NM_001424 & Epithelial membrane protein 2 & 4.4 & 4.35 & 4.4 \\
\hline ANAPC10 & NM_014885 & $\begin{array}{l}\text { Anaphase promoting complex } \\
\text { subunit } 10\end{array}$ & 3.05 & 3.65 & 3.4 \\
\hline YWHAH & NM_003405 & $\begin{array}{l}\text { Tryptophan 5-monooxygenase } \\
\text { activation protein, eta } \\
\text { polypeptide }\end{array}$ & 2.8 & 3 & 2.9 \\
\hline$S A R 1 B$ & $\begin{array}{l}\text { NM_001033503, } \\
\text { NM_016103 }\end{array}$ & SAR1 homolog B & 2.65 & 2.45 & 2.8 \\
\hline SEMA6D & $\begin{array}{l}\text { NM_020858, NM_024966, } \\
\text { NM_153616,N M_153617, } \\
\text { NM_153618, NM_153619 }\end{array}$ & $\begin{array}{l}\text { Sema domain, transmembrane } \\
\text { domain (TM), and cytoplasmic } \\
\text { domain, (semaphorin) 6D }\end{array}$ & 2.45 & 2.7 & 2.6 \\
\hline SEMA4F & NM_004263 & $\begin{array}{c}\text { Sema domain, immunoglobulin } \\
\text { domain (Ig), transmembrane } \\
\text { domain (TM) and short } \\
\text { cytoplasmi }\end{array}$ & 2.8 & 2.4 & 2.6 \\
\hline$Q K I$ & $\begin{array}{l}\text { NM_006775, NM_206853, } \\
\text { NM_206854,NM_206855 }\end{array}$ & $\begin{array}{l}\text { Quaking homolog, KH domain } \\
\text { RNA binding }\end{array}$ & 2.15 & 2.75 & 2.5 \\
\hline TGFB2 & NM_001135599,NM_003238 & Transforming growth factor, beta 2 & 2.95 & 2.1 & 2.5 \\
\hline CREBL2 & NM_001310 & $\begin{array}{l}\text { cAMP responsive element binding } \\
\text { protein-like } 2\end{array}$ & -5.6 & -7.6 & -6.6 \\
\hline YWHAE & NM_006761, NR_024058 & $\begin{array}{l}\text { Tryptophan 5-monooxygenase } \\
\text { activation protein, epsilon polypep }\end{array}$ & -4 & -4.6 & -4.3 \\
\hline PLEKHAЗ & NM_019091 & $\begin{array}{c}\text { pleckstrin homology domain } \\
\text { containing, family A }\end{array}$ & -3.4 & -4 & -3.7 \\
\hline NSA2 & NM_014886 & NSA2 ribosome biogenesis homolog & -3.05 & -3.95 & -3.5 \\
\hline CDC138 & NM_144978 & Coiled-coil domain containing 138 & -3.8 & -3.05 & -3.4 \\
\hline GPATCH4 & NM_015590, NM_182679 & G patch domain containing 4 & -2.9 & -2.9 & -2.9 \\
\hline KIF3B & NM_004798 & Kinesin family member 3B & -2.55 & -3.3 & -2.9 \\
\hline$R N F 138$ & $\begin{array}{c}\text { NM_001191324,NM_016271, } \\
\text { NM_198128 }\end{array}$ & Ring finger protein 138 & -2.5 & -2.5 & -2.5 \\
\hline$C D C 14 B$ & $\begin{array}{c}\text { NM_00107718181,NM_003671, } \\
\text { NM_033331 }\end{array}$ & $\begin{array}{c}\text { CDC14 cell division cycle } 14 \\
\text { homolog B }\end{array}$ & -2.35 & -2.7 & -2.5 \\
\hline UBE2Q1 & NM_017582 & $\begin{array}{l}\text { Ubiquitin-conjugating enzyme E2Q } \\
\text { family member } 1\end{array}$ & -2.25 & -2.85 & -2.5 \\
\hline
\end{tabular}

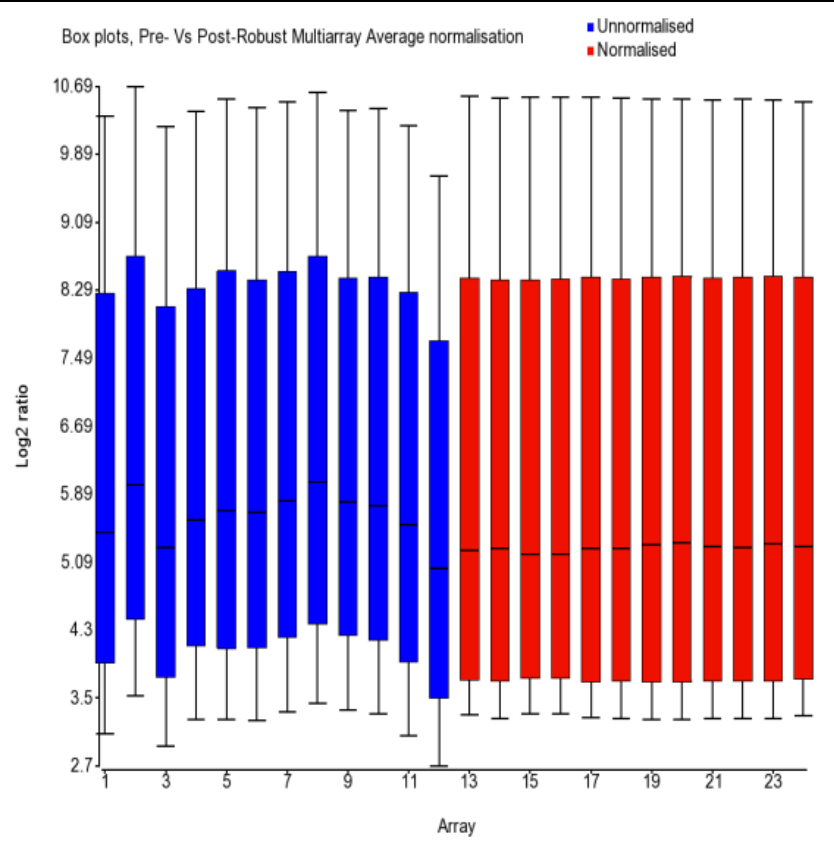

Figure 3. Box plot of all samples pre and post normalisation. Each sample represented by one box plot. The blue box plots represent log2 ratio for raw intensity values, and the red box plots represent log2 ratio for normalised data

Total TNC knockdown induced significant differential gene expression in highly invasive breast cancer cell lines at 48 hours post-transfection. The differential gene expression was directly proportional to transaction period as indicated by less alteration at 24 hours. Hierarchical clustering was performed on all samples using complete linkage and incorporating the log2 ratios for all markers (54,680 individual markers) on the chip. Firstly, this revealed a large natural difference in gene expression profile between the two native cell lines. Secondly, cDNA derived from the two cell lines also separated based on siRNA treatment and time point. Importantly, sample replicates at $48 \mathrm{hrs}$ in each cell line and treatment also gave good reproducibility clustered together in individual clusters (Figure 2). Box-plots which identify the intensity distribution across the probe values for each sample pre and post normalisation is shown in (Figure 3). There were variations in the distribution of intensity signals among the array before normalisation, which were then corrected and became equal for all samples. Comparative analysis of total TNC siRNA to scrambled control mRNA profiles showed differential regulation of 156 overlapping in both cell lines, of which 106 (68\%) were up-regulated and 44 (32\%) were down-regulated (Figure 4). There were 329 and 417 up- or down-regulated genes unique to each cell line. The difference between the unique number of affected genes in each cell line and at each time point is perhaps a reflection of the alternate effects of TNC knockdown on each and the subsequent coping mechanisms adopted in response to this knockdown.

Messenger RNA (mRNA) levels regulated by more than two-fold changes top 20 overlapping genes in both breast cell lines were listed in (Table 1). Of the top 20 
overlapping genes, four candidate genes (CREBL2, YWHAE, RRAS2 and QKI) were selected for further validation according to their role in cancer, particularly those associated with cancer cell invasion and proliferation.

\section{Scrambled siRNA Vs Total TNC siRNA}
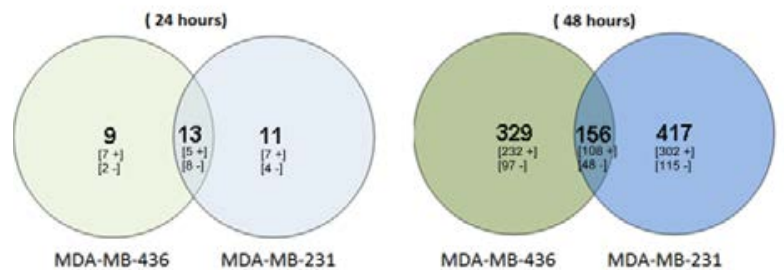

Figure 4. Venn diagram reveals overlapping genes amongst breast cancer cell lines that are differentially regulated as a result of total TNC knockdown in MDA-MB-436 and -231 cells at 24 and 48 hrs
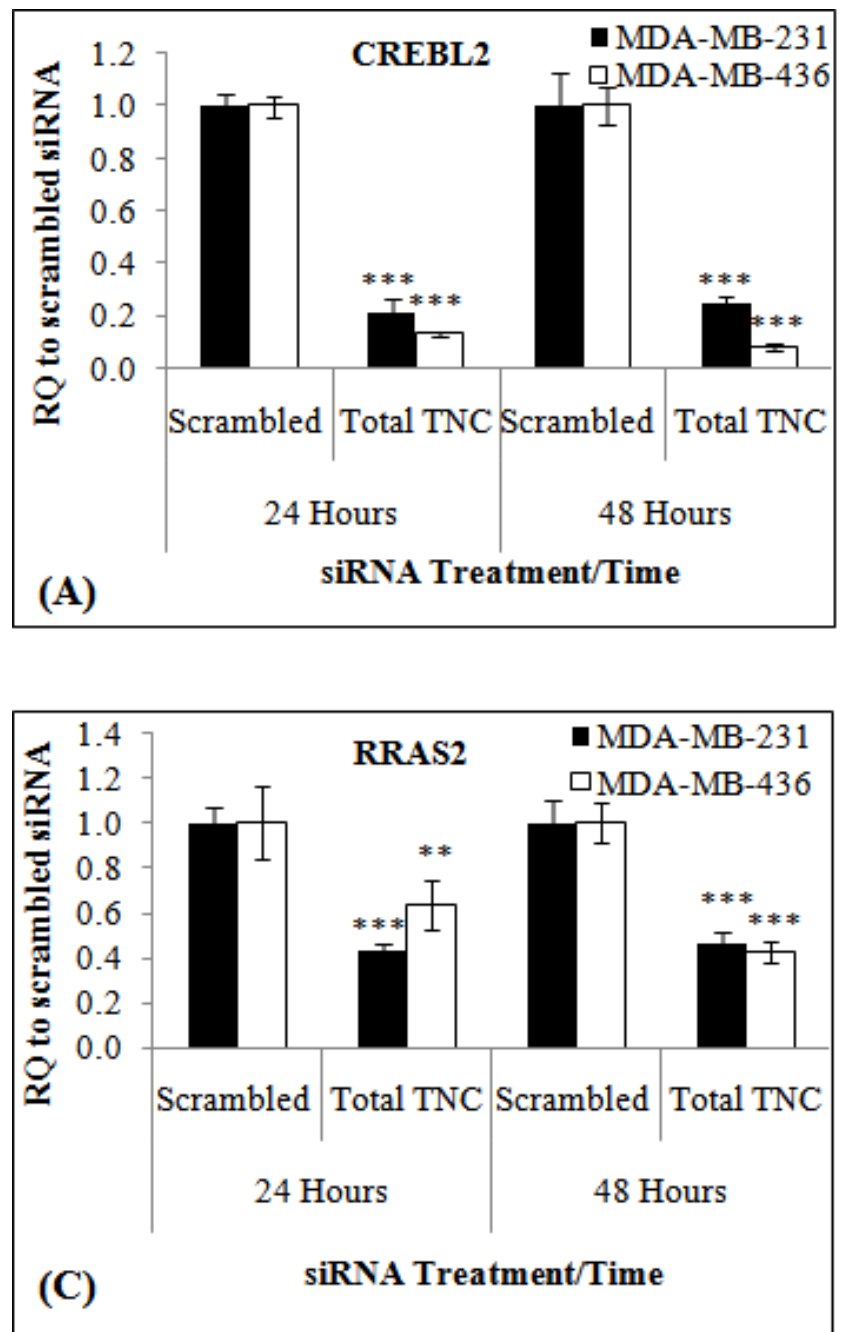

\subsection{Real Time Quantitative PCR Analysis of Differential Gene Expression}

Real time quantitative (RT-qPCR) analysis of the four candidate genes confirmed the effects of total TNC knockdown on candidate gene expression and significantly correlated with GeneChip analysis of both breast cancer cell lines (MDA-MB-231 and MDA-MB436) transfected with total TNC siRNA at 24 hours and 48 hours. Furthermore, RT-qPCR analyses of down-regulated genes (CREBL2, YWHAE, RRAS2) (Figure 5 A,B,C), and up-regulated genes $(Q K I)$ (Figure $5 \mathrm{D}$ ) showed similar results with GeneChip analysis; whereas there was some variance found with $Q K I$. For example, there were no significant changes shown in QKI expression in both cell lines at $24 \mathrm{hrs}$ post transfection.
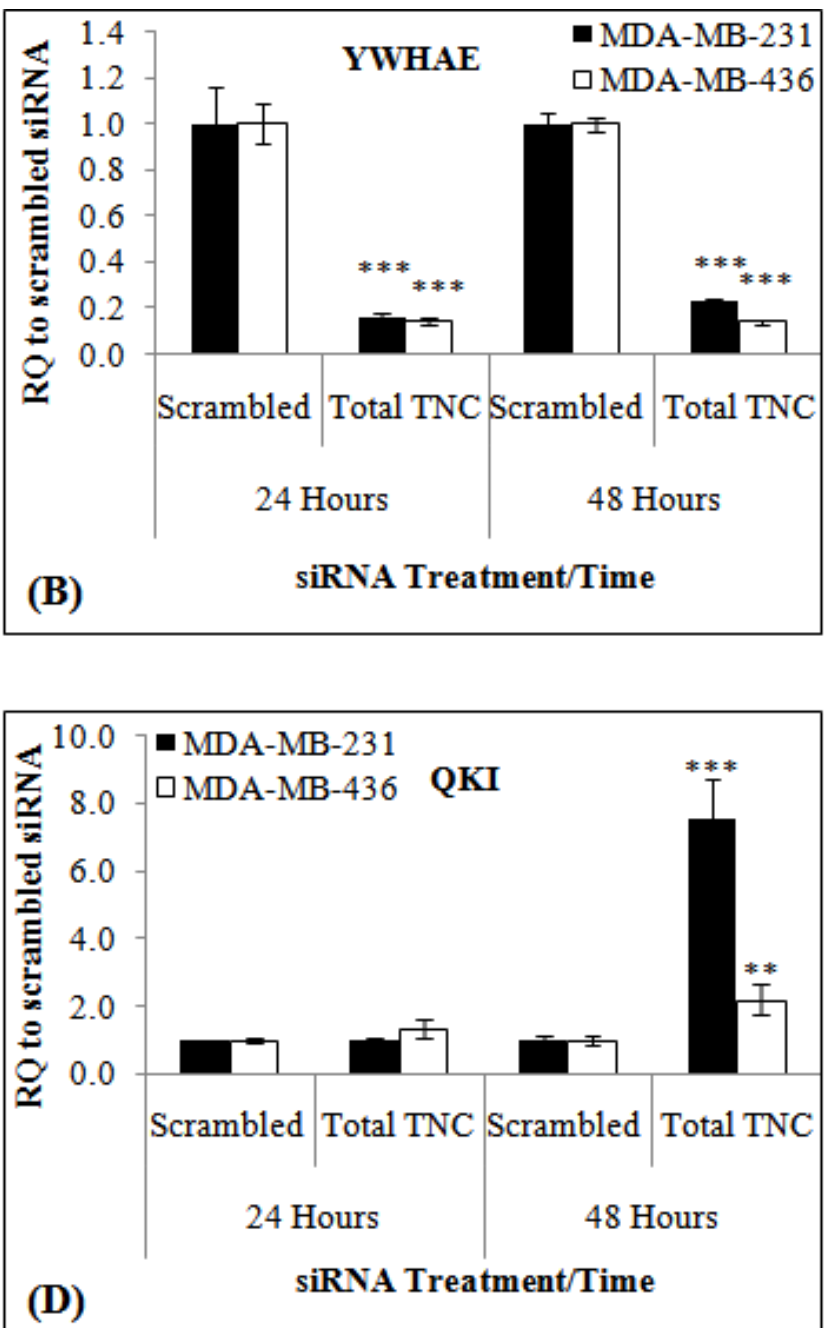

Figure 5. Relative quantitation (RQ) values of regulated genes in transfected MDA-MB-231 and MDA-MB-436 breast cancer cell line with total TNC siRNA compared to scrambled siRNA control. The graph shows the mean RQ value ( \pm SEM) between samples compared to scrambled siRNA. Significant differences $(* *=\mathrm{p} \leq 0.01 ; * * *=\mathrm{p} \leq 0.001)$ are indicated by asterisks

3.3. Effects of TNC Knockdown on Genes Associated with ECM and Tumour Progression

The KEGG pathway analysis by Database for Annotation, Visualization and Integrated Discovery
(DAVID) (Table 2) identified 72 genes associated with different pathways involved in the development of cancer, in particular signalling pathways associated with the interactions between cells and ECM. 
Table 2. Pathway analysis in of the regulated genes associated with cancer progression

\begin{tabular}{|c|c|c|c|}
\hline Pathway & $\begin{array}{c}\text { Genes } \\
\text { count }\end{array}$ & p-value & Genes identified \\
\hline $\begin{array}{c}\text { Pathways in } \\
\text { cancer }\end{array}$ & 32 & $1.4 \mathrm{E}^{-03}$ & $\begin{array}{c}\text { BID, E2F2, FGFR3, WNT5B, XIAP, ARNT2, EGLN3, TCF7L2, MMP1, SUFU, TGFB2, } \\
\text { LAMB2, PIK3CA, PIK3R5, CCNA1, AXIN2, FN1, BMP4, COL4A4, FZD8, COL4A2, BMP2, } \\
\text { RET, TGFBR2, CDK6, SMAD2, BAD, BIRC3, COL4A6, WNT2B, PIAS2, WNT9A }\end{array}$ \\
\hline $\begin{array}{c}\text { ECM-receptor } \\
\text { interaction }\end{array}$ & 13 & $1.7 \mathrm{E}^{-03}$ & $\begin{array}{c}\text { COL4A4, COL4A2, TNC, COL5A2, COL4A6, COL5A1, HMMR, ITGA9, LAMB2, ITGB8, } \\
\text { RELN, TSP-1, FN1 }\end{array}$ \\
\hline Focal adhesion & 21 & $5.8 \mathrm{E}^{-03}$ & $\begin{array}{r}\text { COL4A4, COL4A2, FLT1, XIAP, TNC, BAD, BIRC3, COL5A2, COL5A1, COL4A6, PAK6, } \\
\text { ITGA9, LAMB2, ITGB8, PIK3CA, PIK3R5, PDGFC, RELN, TSP-1, SHC4, FN1 }\end{array}$ \\
\hline Cell cycle & 7 & $7.2 \mathrm{E}^{-04}$ & YWHAH, CDC14B, SMAD2, ANAPC10, CCNA1, YWHAE, TGFB2 \\
\hline $\begin{array}{c}\text { TGF-beta } \\
\text { signalling }\end{array}$ & 11 & $1.9 \mathrm{E}^{-02}$ & INHBB, BMP4, NOG, BMP2, SMAD6, FST, GDF5, TGFBR2, SMAD2, TSP-1, TGFB2 \\
\hline ErbB signalling & 10 & $4.5 \mathrm{E}^{-02}$ & PAK6, ERBB4, EREG, ERBB3, PIK3CA, PIK3R5, BAD, AREG, NRG1, SHC4 \\
\hline Apoptosis & 10 & $4.5 \mathrm{E}^{-02}$ & BID, XIAP, PRKAR1A, PIK3CA, PIK3R5, BAD, PRKACB, BIRC3, IL1A, NGF \\
\hline
\end{tabular}

\section{Discussion}

TNC may regulates various genes involved in carcinogenesis as revealed by microarray analysis of total TNC knockdown in breast cancer cell lines in our study, which were differentially regulated at the mRNA level. Although the vast majority of genes that were significantly altered in cells transfected with total TNC siRNA were unique to each cell line, 156 genes were commonly altered in both. Furthermore, the majority of changes were achieved at 48 hrs post-transfection in both cell lines.

Pathway analysis showed the effects of TNC silencing on differential gene expression was associated with several pathways, which relate to the development of cancer, such as focal adhesion, cell cycle, ECM-receptor interaction, TGF-beta signalling, MAPK, ErbB signalling, TP53 and apoptosis. However, the majority of the identified genes were associated with focal adhesion pathways. Cell adhesions play a fundamental role in cell biological signatures including proliferation, motility, differentiation and survival [10]. In this study, focal adhesion was the most common pathway regulated by TNC silencing, and most of the differentially regulated genes were up-regulated, suggesting that TNC silencing stimulates cell adhesion and inhibits cell proliferation and tumour progression. For example, increased level of integrin $\alpha 9$ (ITGA9) is associated with reduced breast cancer cell proliferation and migration [11], and integrin $\alpha 8$ (ITGA8) was found to be a biomarker for ovarian cancer [12].

RT-qPCR Validation of total TNC knockdown showed consistent results for CREBL2, YWHAE, RRAS2 and QKI in both breast cancer cell lines (MDA-MB-231 and MDAMB-436). The information related to the role of CREBL2 in cancer is limited; however, up-regulation of CREBL2 plays an important role in multiple steps of breast cancer bone metastasis [13]. CREBL2 was found to be upregulated during preadipocyte differentiation [14]. These findings suggest TNC may play a critical role in the suppression of adipogenesis and lipogenesis when silencing CREBL2.

YWHAE belongs to the 14-3-3 protein family [15]. 143-3 proteins regulate several intracellular processes such as phosphorylation dependent switching and proteinprotein interactions [16]. In the microarray analysis of breast cancer tissues from patients with different clinical outcomes (relapse and without relapse after 72 months from surgery), 6 genes including YWHAE were upregulated and found to be associated with disease free and overall survival. The expression of YWHAE was associated with shorter disease free and early death confirmed by using covariates of significant factor such as oestrogen receptor (ER-) and lymph node status ( $\mathrm{LN}+$ ) [17]. These findings suggests, the knockdown of total TNC may decrease the oncogenic activity of YWHAE.

RRAS2 (TC21) was shown to regulate key physiological processes in tumour cells such as proliferation, epithelial mesenchymal transition (EMT), migration, anoikis and chemotherapy resistance $([18,19,20])$. RRAS2 was also found to be over-expressed in tumours such as breast, lymphomas, skin carcinomas, oral cavity and oesophageal cancers [18]. RRAS2 was found to be over expressed in 7 out of 9 breast tumour cell lines, suggesting the ability of RRAS2 over-expression in the contribution of breast cancer development [21].

QKI was suggested to have a tumour suppressor action by which it was found to be significantly reduced in tumours such as breast, bladder, testis, ovary, cervix and colon cancer with abnormal reduction in the histone variant (macro H2A1) [22]. QKI expression was also significantly reduced in gastric cancer tissues, predominantly due to promoter hyper-methylation. In addition, down regulation of QKI expression was associated with impaired differentiation, invasion, gastric lymph node metastasis, distant metastasis, advanced TNM stage and poor prognosis [23]. The increase in QKI expression by TNC knockdown, supports the hypothesis that $Q K I$ is a tumour suppressor gene.

\section{Conclusion}

The study has confirmed that TNC knockdown by siRNA affects global gene expression (CREBL2, YWHAE, $R R A S 2$ and $Q K I)$ at the mRNA level. These findings could provide a new mechanism of TNC action in tumorigenesis.

\section{Acknowledgment}

The author would like to thank Dr Kevin Blighe for analytical assistance.

\section{References}

[1] Daley, W.P., Peters, S.B. \& Larsen, M. 2008, "Extracellular Matrix Dynamics In Development And Regenerative Medicine", Journal Of Cell Science, Vol. 121, No. 3, Pp. 255-264.

[2] Ishihara, A., Yoshida, T., Tamaki, H. \& Sakakura, T. 1995, "Tenascin Expression In Cancer Cells And Stroma Of Human 
Breast Cancer And Its Prognostic Significance", Clinical Cancer Research, Vol. 1, No. 9, Pp. 1035-1041.

[3] Orend, G., Huang, W.T., Olayioye, M.A., Hynes, N.E. \& ChiquetEhrismann, R. 2003, "Tenascin-C Blocks Cell-Cycle Progression Of Anchorage-Dependent Fibroblasts On Fibronectin Through Inhibition Of Syndecan-4", Oncogene, Vol. 22, No. 25, Pp. $3917-$ 3926.

[4] Ruiz, C., Huang, W.T., Hegi, M.E., Lange, K., Hamou, M.F., Fluri, E., Oakeley, E.J., Chiquet-Ehrismann, R. \& Orend, G. 2004, "Dilfferential Gene Expression Analysis Reveals Activation Of Growth Promoting Signaling Pathways By Tenascin-C", Cancer Research, Vol. 64, No. 20, Pp. 7377-7385.

[5] Orend, G. 2005a, "Potential Oncogenic Action Of Tenascin-C In Tumorigenesis", International Journal Of Biochemistry \& Cell Biology, Vol. 37, No. 5, Pp. 1066-1083.

[6] Adams, M., Jones, J.L., Walker, R.A., Pringle, J.H. \& Bell, S.C. 2002, "Changes In Tenascin-C Isoform Expression In Invasive And Preinvasive Breast Disease", Cancer Research, Vol. 62, No. 11, Pp. 3289.

[7] Guttery, D.S., Hancox, R.A., Mulligan, K.T., Hughes, S., Lambe, S.M., Pringle, J.H., Walker, R.A., Jones, J.L. \& Shaw, J.A. 2010a, "Association Of Invasion-Promoting Tenascin-C Additional Domains With Breast Cancers In Young Women", Breast Cancer Research, Vol. 12, No. 4, Pp. R57.

[8] Bolstad, B.M., Irizarry, R.A., Astrand, M. \& Speed, T.P. 2003, "A Comparison Of Normalization Methods For High Density Oligonucleotide Array Data Based On Variance And Bias", Bioinformatics, Vol. 19, No. 2, Pp. 185-193.

[9] J. Jackson And Nancy Standart (2 January 2007) "How Do Micrornas Regulate Gene Expression?" Sci. STKE 2007 (367), Re1.

[10] Petit, V. \& Thiery, J.P. 2000, "Focal Adhesions: Structure and Dynamics", Biology Of The Cell, Vol. 92, No. 7, Pp. 477-494.

[11] Mostovich, L.A., Prudnikova, T.Y., Kondratov, A.G., Loginova, D., Vavilov, P.V., Rykova, V.I., Sidorov, S.V., Pavlova, T.V., Kashuba, V.I., Zabarovsky, E.R. \& Grigorieva, E.V. 2011, "Integrin Alpha9 (ITGA9) Expression And Epigenetic Silencing In Human Breast Tumors", Cell Adhesion \& Migration, Vol. 5, No. 5, Pp. 395-401.

[12] Cai, L., Abe, M., Izumi, S., Imura, M., Yasugi, T. \& Ushijima, T. 2007, "Identification Of PRTFDC1 Silencing And Aberrant Promoter Methylation Of GPR150, ITGA8 And HOXD11 In Ovarian Cancers", Life Sciences, Vol. 80, No. 16, Pp. 1458-1465.

[13] Son, J., Lee, J., Kim, H., Ha, H. \& Lee, Z.H. 2010, "CampResponse-Element-Binding Protein Positively Regulates Breast Cancer Metastasis And Subsequent Bone Destruction",
Biochemical And Biophysical Research Communications, Vol. 398, No. 2, Pp. 309-314.

[14] Ma, X., Zhang, H., Yuan, L., Jing, H., Thacker, P. \& Li, D. 2011, "CREBL2, Interacting With CREB, Induces Adipogenesis In 3T3L1 Adipocytes", Biochemical Journal, Vol. 439, Pp. 27-38.

[15] Tak, H., Jang, E., Kim, S.B., Park, J., Suk, J., Yoon, Y.S., Ahn, J.K., Lee, J. \& Joe, C.O. 2007, "14-3-3epsilon Inhibits MK5Mediated Cell Migration By Disrupting F-Actin Polymerization", Cellular Signalling, Vol. 19, No. 11, Pp. 2379-2387.

[16] De, S., Marcinkiewicz, J.L., Vijayaraghavan, S. \& Kline, D. 2012, "Expression Of 14-3-3 Protein Isoforms In Mouse Oocytes, Eggs And Ovarian Follicular Development.", BMC Research Notes, Vol. 5, Pp. 57-57.

[17] Cimino, D., Fuso, L., Sfiligoi, C., Biglia, N., Ponzone, R., Maggiorotto, F., Russo, G., Cicatiello, L., Weisz, A., Taverna, D., Sismondi, P. \& De Bortoli, M. 2008, "Identification Of New Genes Associated With Breast Cancer Progression By Gene Expression Analysis Of Predefined Sets Of Neoplastic Tissues", International Journal Of Cancer, Vol. 123, No. 6, Pp. 1327-1338.

[18] Alarcon, B. \& Martinez-Martin, N. 2012, "Rras2, Rhog And TCell Phagocytosis.", Small Gtpases, Vol. 3, No. 2, Pp. 97-101.

[19] Larive, R.M., Abad, A., Cardaba, C.M., Hernandez, T., Canamero, M., De Alava, E., Santos, E., Alarcon, B. \& Bustelo, X.R. 2012 "The Ras-Like Protein R-Ras2/TC21 Is Important For Proper Mammary Gland Development", Molecular Biology Of The Cell, Vol. 23, No. 12, Pp. 2373-2387.

[20] Rokavec, M., Schroth, W., Amaral, S.M.C., Fritz, P., Antoniadou, L., Glavac, D., Simon, W., Schwab, M., Eichelbaum, M. \& Branch, H. 2008, "A Polymorphism In The TC21 Promoter Associates With An Unfavorable Tamoxifen Treatment Outcome In Breast Cancer", Cancer Research, Vol. 68, No. 23, Pp. 97999808.

[21] Clark, G., Kinch, M., Gilmer, T., Burridge, K. \& Der, C. 1996, "Overexpression Of The Ras-Related TC21/R-Ras2 Protein May Contribute To The Development Of Human Breast Cancers", Oncogene, Vol. 12, No. 1, Pp. 169-176.

[22] Novikov, L., Park, J.W., Chen, H., Klerman, H., Jalloh, A.S. \& Gamble, M.J. 2011, "QKI-Mediated Alternative Splicing Of The Histone Variant Macroh2a1 Regulates Cancer Cell Proliferation", Molecular And Cellular Biology, Vol. 31, No. 20, Pp. 4244-4255.

[23] Bian, Y., Wang, L., Lu, H., Yang, G., Zhang, Z., Fu, H., Lu, X., Wei, M., Sun, J., Zhao, Q., Dong, G. \& Lu, Z. 2012 "Downregulation Of Tumor Suppressor QKI In Gastric Cancer And Its Implication In Cancer Prognosis", Biochemical And Biophysical Research Communications, Vol. 422, No. 1, Pp. 187193 